\title{
Wii-based exercise program to improve physical fitness, motor proficiency and functional mobility in adults with Down syndrome
}

\author{
V. Silva, ' C. Campos, ${ }^{2}$ A. Sá, ' M. Cavadas, ' J. Pinto,' P. Simões, ' S. Machado, ${ }^{2}$ iif \\ E. Murillo-Rodríguez ${ }^{3} \&$ N. Barbosa-Rocha' (D) \\ I Polytechnic Institute of Porto, Health School, Porto, Portugal \\ 2 Panic and Respiration Laboratory, Institute of Psychiatry, Federal University of Rio de faneiro, Brazil \\ 3 División Ciencias de la Salud, Escuela de Medicina, Universidad Anahuac Mayab Laboratorio de Neurociencias Moleculares e \\ Integrativas, Merida, Mexico
}

\begin{abstract}
Background People with Down syndrome (DS) usually display reduced physical fitness (aerobic capacity, muscle strength and abnormal body composition), motor proficiency impairments (balance and postural control) and physical functional limitations. Exergames can be an appealing alternative to enhance exercise engagement and compliance, whilst improving physical fitness and motor function. This study aims to analyse the effects of a Wii-based exercise program on physical fitness, functional mobility and motor proficiency of adults with DS.

Methods Twenty-seven adults with DS were randomly allocated to an experimental group (Wii; $n=14)$ or control group $(n=13)$. Participants in the experimental group completed a 2-month Wii-based exercise program, with three I-h sessions per week that included training games for aerobic endurance, balance and isometric strength. Participants completed assessments regarding anthropometric measures, physical fitness, functional mobility and motor proficiency.
\end{abstract}

Correspondence: Dr. Nuno Rocha, Polytechnic Institute of Porto, Health School, Porto, Portugal (e-mail: nrocha@ess.ipp.pt).
Results Mixed ANOVA analysis showed a significant group by time interaction for aerobic endurance, explosive leg power and flexibility. Independent samples $t$-test for change scores indicated significant between-group differences favouring the experimental group regarding speed of limb movement, trunk strength and functional mobility, as well as a trend towards significance on body weight. Mann-Whitney's $U$ test for change scores demonstrated between-group differences favouring the experimental group for visceral fat as well as running speed and agility. Large within-group effect sizes were observed for explosive leg power ( $d=\mathrm{I} .69 \mathrm{I})$, body weight $(d=\mathrm{I} .28 \mathrm{I})$, functional mobility $(d=\mathrm{I} .2 \mathrm{I} 8)$, aerobic endurance $(d=\mathrm{I} .020)$, speed of limb movement $(d=0.867)$ and flexibility $(d=0.8 \mathrm{I} 8)$ in the experimental group.

Conclusions Our findings suggest that Wii-based exercise can be an effective tool to improve physical fitness, functional mobility and motor proficiency of adults with DS, including crucial measures such as aerobic capacity and lower limb strength. Exergames using Wii Fit or other equipment can be appealing alternatives for adults with DS to engage in regular physical activity, preventing sedentary behaviour and decreasing the risk to develop cardiovascular diseases. 
V. Silva et al. • Wii exercise adult Down syndrome

Keywords Down syndrome, exercise, exergames, functional mobility, motor proficiency, physical fitness

\section{Introduction}

Down Syndrome (DS) is a chromosomal anomaly caused by a trisomy during conception (Presson et al. 2013) that results in an additional copy of chromosome 2I (de Graaf et al. 20II) and has a prevalence between 6.I and I3.I per I0.000 people (Presson et al. 2013). There is also a large amount of evidence describing diminished physical fitness in people with DS (González-Agüero et al. 20Io; Pitetti et al. 2013), including reduced aerobic capacity or cardiorespiratory fitness (Baynard et al. 2008; Mendonca et al. 2010; Fernhall et al. 2013), diminished muscular strength (Pitetti et al. I992; Carmeli et al. 2002) and abnormal body composition (van Gameren-Oosterom et al. 2012; Jiménez et al. 2015; Bertapelli et al. 2016). These physical fitness shortfalls, mainly lower levels of strength and endurance, lead to high levels of energy expenditure during daily live activities by individuals with DS (Horvat et al. I997; Mercer \& Lewis 200I). Greater energy expenditure can decrease physical activity tolerance, predisposing individuals with DS to sedentary lifestyles.

People with DS also display generalised muscle hypotonia, ligamentous laxity, articular hypermobility and difficulties in agonist and antagonist muscle cocontraction (Lewis \& Fragala-Pinkham 2005).

Consequently, they experience changes in dynamic balance, postural control and other motor proficiency domains, as they are slower to adapt to motor task demands and environmental changes and have less ability to perform anticipatory postural adjustments (Shields et al. 2008). These changes also impair visual motor integration, agility, muscle strength, motor control and movement reaction time (Rigoldi et al. 20II; Wuang \& Su 20I2). Furthermore, muscle weakness and hypotonia seem to impair upper limb movements and gait performance (Galli et al. 2008a). In people with DS, lower limb strength is essential for their overall physical health and to daily activity performance (Cioni et al. 1994; Horvat et al. 1997). People with DS usually engage in vocational activities that demand physical rather than cognitive skills, and reduced strength can hinder the development of their work-related roles (Shields et al. 2008).

Thereby, the importance of encouraging physical activity and exercise for people with DS cannot be underestimated. Cowley et al. (20I0) showed that adults with DS who were more physically fit displayed better performance on functional tasks such as walking, rising from a chair and ascending/descending steps. There are several systematic reviews suggesting that exercise interventions can effectively improve cardiovascular fitness (Dodd \& Shields 2005), muscle strength and balance (Li et al. 2013) as well as daily life activities and social participation in individuals with DS (Hardee \& Fetters 2017). Also, there is a growing recognition that exercise can promote positive cognitive changes associated with exercise-induced trophic factor enhancement, which further encourages exercise interventions (Campos et al. 2016).

More recently, exergames have been highlighted as an appealing alternative to promote physical activity. Exergames have been explored in a wide range of conditions (Hsu et al. 20I I; Nilsagard et al. 2013; Campos et al. 20I5; Jaarsma et al. 2015) and across several age groups (Franco et al. 2012; Chiu et al. 20I4; Hammond et al. 20I4; Jelsma et al. 20I4; Park et al. 20I4; Jung et al. 2015). Exergames consist of video games that demand physical activity, such as Wii Fit and Wii Sports, allowing participants to achieve the recommended aerobic exercise intensity and energy expenditure (Lanningham-Foster et al. 2009; Douris et al. 2012; LeGear et al. 2016).

Furthermore, interventions using exergames may be better than traditional programs regarding motivation and compliance. Individuals who received Wii generally report increased enjoyment and engagement (Franco et al. 2012; Yuen et al. 2013; Tatla et al. 20I4). The affective response to exercise has been widely related to exercise adherence, as participants are more likely to continuously engage in exercise programs if they previously experienced positive affective responses (Williams 2008; Lee et al. 2016). Thereby, exergames can be a valuable tool to increase exercise compliance, allowing programs to effectively facilitate energy expenditure, promote physical fitness, improve sensorimotor functions and prevent sedentary behaviour.

Although there are a few studies exploring the feasibility and efficacy of exergame interventions for children and adolescents with DS (Wuang et al. 20I I;

(C) 2017 MENCAP and International Association of the Scientific Study of Intellectual and Developmental Disabilities and John Wiley \& Sons Ltd 
Berg et al. 20I2; Lin \& Wuang 20I2), there are no studies addressing its effectiveness for adults with DS. This study aims to analyse the effects of a Wii-based exercise program on physical fitness, functional mobility and motor proficiency of adults with DS.

\section{Methods}

\section{Participants}

Adults diagnosed with DS, aged between I8 and 60 years, were recruited from the following occupational centres: Centro de Actividades Ocupacionais de Areosa da Associação Portuguesa de Pais e Amigos do Cidadão Deficiente Mental de Viana do Castelo and Cooperativa de Educação e Reabilitação de Cidadãos Inadaptados de Guimarães. Participants were excluded if they had any kind of neuromusculoskeletal disorder or severe sensory impairments. Subjects that performed any sort of regular physical exercise or sports were also excluded.
Thirty-two participants were assessed for eligibility. Five participants were excluded, either by not being in compliance with the inclusion criteria $(n=3)$, withdrawing from the study $(n=\mathrm{I})$ or leaving the country after the initial assessment $(n=\mathrm{I})$. Therefore, 27 participants were randomly allocated to the experimental group (Wii-based exercise program; $n=\mathrm{I} 4$ ) or control group ( $n=\mathrm{I} 3$ ), using a block randomisation by gender. There were two dropouts in the experimental group, and thus, 25 participants completed all the intervention sessions and assessment procedures (Fig. I).

\section{Instruments}

Regarding anthropometric measurements, height was measured by using a stadiometer with a $0 . \mathrm{I}-\mathrm{cm}$ accuracy. Waist circumference was measured at the narrowest point between the external surface of the last rib and the anterior superior iliac spine, using a

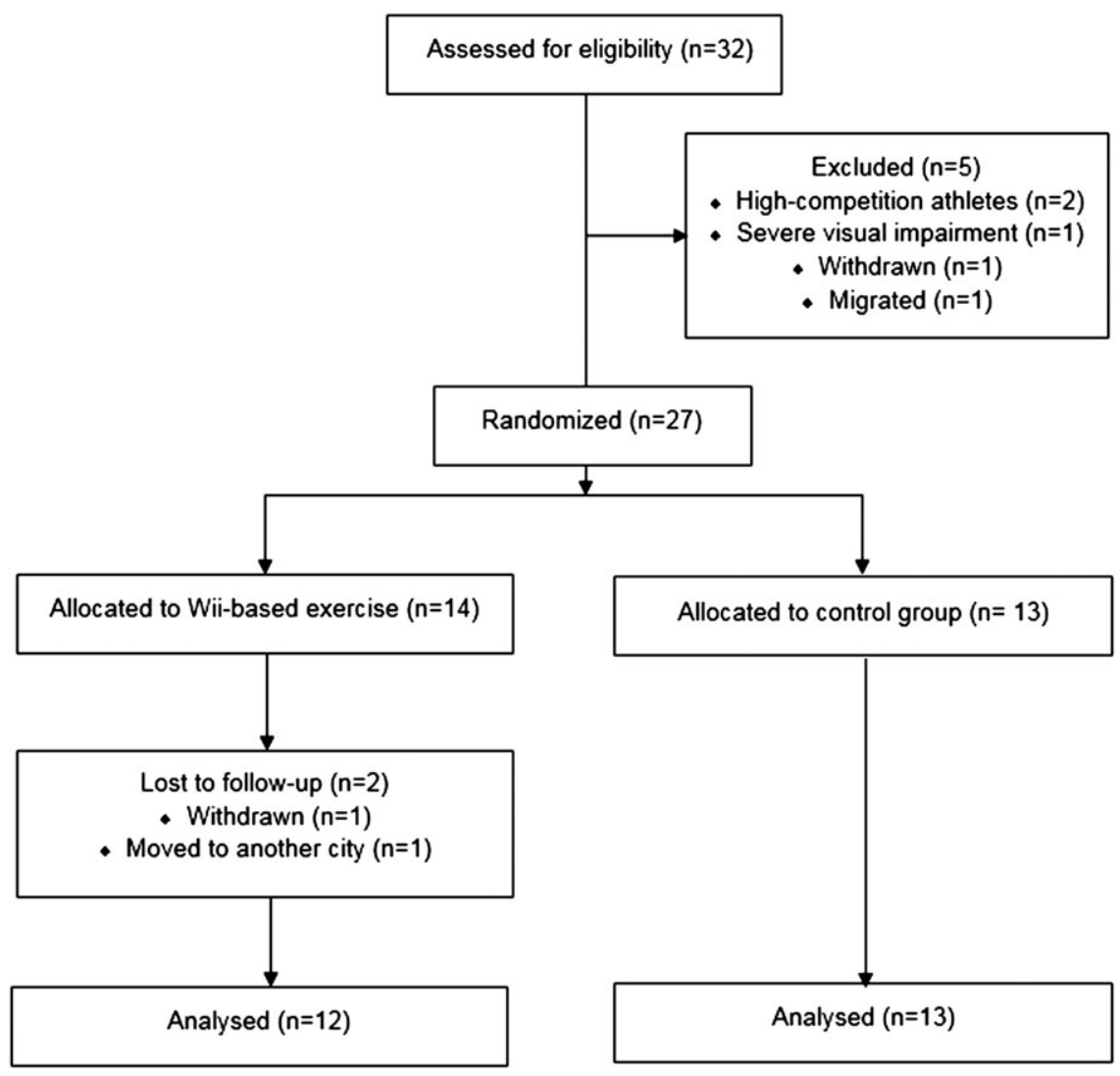

Figure I Flow chart for selection of study participants.

(C) 2017 MENCAP and International Association of the Scientific Study of Intellectual and Developmental Disabilities and John Wiley \& Sons Ltd 
steel anthropometric tape with $0.0 \mathrm{I}-\mathrm{m}$ intervals. Weight, body mass index (BMI), body fat percentage, visceral fat levels and muscle mass were obtained by using a segmental body composition analyser (Tanita BC 53I).

Physical fitness was assessed by using the Eurofit Test Battery (Oja \& Tuxworth I995), allowing to evaluate numerous fitness domains, namely, speed of limb movement (Plate Tapping Test), static arm strength (Handgrip Test), running speed and agility (Shuttle Run), balance (Flamingo Balance Test), flexibility (Sit and Reach Test), explosive leg power (Standing Broad Jump), trunk strength (30-sec SitUps), muscular endurance (Bent Arm Hang) and aerobic endurance (Six-Minute Walk). The Eurofit Test Battery has been proven as a reliable tool to assess physical fitness in people with IDs, with intraclass correlation coefficients between 0.94 and 0.99 (MacDonncha et al. 1999)

Secondary outcome measures included the Timed Up \& Go Test to assess functional mobility (Podsiadlo \& Richardson I99I) and the response speed subtest of the Bruininks-Oseretsky Test of Motor Proficiency First Edition (Bruininks 1978) and the beanbag overhead throw (Carmeli et al. 2008) to assess motor proficiency. The Timed Up \& Go Test has been proven as a reliable tool to assess functional mobility in individuals with DS, with excellent intrasession reliability (intraclass correlation coefficient $=0.93^{-0.95)}$ and reproducibility $(0.82)$ (Nicolini-Panisson \& Donadio 2014). The use of motor proficiency tasks with subjects with IDs has been reported (Connolly \& Michael I986; Carmeli et al. 2012).

\section{Procedures}

This study was approved by the Ethics Committee from the Porto Polytechnic Institute Health School, and institutional authorisation was given by both Centro de Actividades Ocupacionais de Areosa da Associação Portuguesa de Pais e Amigos do Cidadão Deficiente Mental de Viana do Castelo and Cooperativa de Educação e Reabilitação de Cidadãos Inadaptados de Guimarães. Initially, study procedures were explained to all potential participants. Families and legal guardians of the individuals interested in participating were contacted and fully informed about the study procedures. Finally, informed consent from both participants themselves and the participant's legal representatives was obtained, according to the Declaration of Helsinki.

Participants were then screened for eligibility and completed the assessment procedures, which were performed by trained researchers blinded to the randomised intervention conditions. Assessment procedures were completed again after the intervention period.

During the intervention period, the experimental group completed a 2-month Wii-based exercise program encompassing up to 22 sessions that were included in the regular occupational therapy program of both institutions. Participants completed three I-h sessions per week, either individually or together with another participant (half the sessions in each format). Individual sessions were performed by using the Wii Fit Balance Board, allowing participants to perform balance and isometric strength exercises provided by the following games: 'free run', 'heading', 'table tilt', 'snowboard slalom', 'tightrope tension', 'hula hoop', 'balance bubble' and 'penguin slide'. Paired sessions mainly targeted aerobic endurance, as participants completed several sports-related and dancing games (Wii Sports, Wii Sports Resort, Wii Fit and fust Dance 2), including 'swordplay', 'boxing', 'cycling', 'table tennis' and 'Just Dance 2'. The control group completed their usual daily activities (treatment-asusual) on their occupational centre such as vocational rehabilitation, life-skill training and art-related activities, among others.

Independent samples $t$-tests were used to verify the differences between the two groups at baseline. A $2 \times 2$ mixed factor analysis of variance was used to test for differences between control condition and exercise intervention (between-group effects) and differences between baseline and post-intervention (within-group effects). Post-hoc analysis was used to assess the effects within each group. Homogeneity of variance and residual normality assumptions were tested by using the Levene's and Shapiro-Wilk tests respectively. If assumptions were not met, change scores for those outcome measures were computed. Change scores for each group were compared by using independent samples $t$-test or Mann-Whitney $U$ tests, depending on the normality of the data. Analyses were led separately for all the outcome variables including anthropometric measures, physical fitness, functional mobility and motor 
proficiency tests. All tests were applied with a significance level of 0.05 .

Effect size analysis for each group was calculated by using Cohen's $d$. Cohen's $d$ is obtained by the difference between the pre-test and post-test average, divided by their common standard deviation. Given that the calculation was for within group effects, we correlated both means and used Morris \& DeShon's (2002) equation. Calculations were completed by using the $\mathrm{G}^{\star}$ POWER software (version 3.I). Effect sizes were classified as small $(d<0.2)$, small to moderate $(d=0.2-0.4)$, moderate to large $(d=0.5-0.8)$ and large $(d>0.8)$ (Lipsey \& Wilson 200I).

\section{Results}

At baseline, there were no significant group differences regarding age, gender, height or any of the outcome measures $(p>0.05)$, with the exception of the Plate Tapping Test $(p=0.048)$. Thereby, it can be assumed that participants in both groups were similar in relevant variables at the moment the intervention began (Table I).

Mixed analysis of variance analysis showed significant group by time interaction on Sit and Reach Test $(p=0.027)$, Standing Broad Jump $(p=0.003)$ and Six-Minute Walk $(p=0.005)$. There were also significant main effects for time on waist circumference $(p=0.009)$, Handgrip Test $(p=0.004)$, Standing Broad Jump $(p<0.00 \mathrm{I})$, Bruininks-Oseretsky Response Speed Subtest $(p=0.034)$ and left-handed Beanbag Overhead Throw $(p=0.040)$. There were no significant interactions or main effects for body fat percentage, muscle mass and right-handed Beanbag Overhead Throw (Table I).

Post-hoc analysis revealed significant improvements in the experimental group after the intervention on waist circumference $(p=0.008)$, Handgrip Test $(p=0.025)$, Sit and Reach Test $(p=0.014)$, Standing Broad Jump ( $p<0.001)$, Six-Minute Walk $(p=0.003)$ and Bruininks-Oseretsky Response Speed Subtest $(p=0.028)$. Participants from the control group also experienced improvements in the Handgrip Test ( $p=0.039$ ) (Table I).

Homogeneity of variance and/or residual normality assumptions were violated for body weight, BMI, visceral fat, Plate Tapping Test, Shuttle Run, Flamingo Balance Test, 30-Sec Sit-Ups, Bent Arm
Hang and TUG. Thereby, independent samples $t$-test or Mann-Whitney $U$ tests were used to compare the change scores between groups for these outcomes. Independent samples $t$-test for change scores indicated significant between-group differences regarding Plate Tapping Test $(p=0.045)$, 30-Sec SitUps $(p=0.040)$ and Timed Up \& Go $(p=0.049)$, as well as a trend towards significant on body weight ( $p=0.059$ ). Mann-Whitney's $U$ test for change scores displayed between-group differences for visceral fat $(p=0.036)$ and Shuttle Run ( $p=0.014)$. Descriptive statistics suggest that participants in the experimental group clearly improved on all these outcome measures, whilst the control group remained fairly unchanged or worsened. Mann-Whitney's $U$ test for change scores also displayed no significant differences between group on BMI, Flamingo Balance Test and Bent Arm Hang (Table I).

\section{Discussion}

To our knowledge, this is the first trial exploring the effects of an exergame intervention on adults with DS. Our findings suggest that Wii-based exercise can improve functional mobility and several physical fitness outcomes in this population including aerobic endurance, running speed and agility, lower extremities and abdominal strength, speed of limb movement and flexibility. It is important to notice that previous studies using Wii-based exercise for children and adolescent with DS have reported similar findings. Wuang et al. (2OII) developed a trial with 105 children with DS in order to compare a 24week (I h, twice a week) Wii Sports gaming intervention with standard occupational therapy. The Wii Sports group significantly improved performance in several motor proficiency measures such as running speed and agility, upper limb coordination and finemotor skills as well as in visual-integrative abilities and sensory integrative functions. Another trial from Lin \& Wuang (2012) combined treadmill exercise and Wii Sports games to engage adolescents with DS in a 6-week strength and agility training (35 min, 3 times per week), reporting significant improvements in agility and muscle strength, especially in the lower extremities. There is also a case report using a homebased 8-week Wii intervention protocol that reported improvements in postural control and several motor skills, namely, running speed and agility, balance, 
V. Silva et al. - Wii exercise adult Down syndrome

Table I Between and within-group comparisons and effect size analysis for all outcome measures

\begin{tabular}{|c|c|c|c|c|c|c|c|c|c|}
\hline \multirow{2}{*}{\multicolumn{2}{|c|}{ Outcome measures }} & \multicolumn{2}{|c|}{$\begin{array}{l}\text { Experimental EG } \\
\qquad(n=\mid 2)\end{array}$} & \multicolumn{2}{|c|}{$\begin{array}{c}\text { Control CG } \\
(n=13)\end{array}$} & \multicolumn{4}{|c|}{ Effect sizes } \\
\hline & & $\begin{array}{l}\text { Pre-mean } \\
\text { (SD) }\end{array}$ & $\begin{array}{c}\text { Post-mean } \\
\text { (SD) }\end{array}$ & $\begin{array}{l}\text { Pre-mean } \\
\text { (SD) }\end{array}$ & $\begin{array}{l}\text { Post-mean } \\
\text { (SD) }\end{array}$ & $P$ & $\begin{array}{l}\text { Between- } \\
\text { group } \eta_{\mathrm{p}}^{2}\end{array}$ & $\begin{array}{l}\text { Within } \\
\text { EG } d_{z}\end{array}$ & $\begin{array}{l}\text { Within } \\
\text { CG d }\end{array}$ \\
\hline \multirow[t]{6}{*}{$\begin{array}{l}\text { Anthropometric } \\
\text { measures }\end{array}$} & Body weight & $\begin{array}{l}72.97 \\
(15.12)\end{array}$ & $\begin{array}{l}71.43 \\
(14.80)\end{array}$ & $\begin{array}{l}70.01 \\
(19.01)\end{array}$ & $\begin{array}{l}69.65 \\
(17.4 I)\end{array}$ & $0.059^{\dagger}$ & - & 1.281 & 0.158 \\
\hline & Body mass index & $\begin{array}{l}32.20 \\
(6.35)\end{array}$ & $\begin{array}{l}32.42 \\
(6.24)\end{array}$ & $\begin{array}{l}32.04 \\
(6.92)\end{array}$ & $\begin{array}{l}31.89 \\
(6.80)\end{array}$ & $0.367^{\ddagger}$ & - & 0.077 & 0.197 \\
\hline & Body fat $\%$ & $\begin{array}{l}29.60 \\
(11.57)\end{array}$ & $\begin{array}{l}28.50 \\
(12.18)\end{array}$ & $\begin{array}{l}31.19 \\
(8.13)\end{array}$ & $\begin{array}{l}31.30 \\
(8.66)\end{array}$ & $0.240 *$ & 0.060 & 0.766 & 0.035 \\
\hline & Visceral fat & $\begin{array}{c}9.04 \\
(3.65)\end{array}$ & $\begin{array}{l}7.79 \\
(2.93)\end{array}$ & $\begin{array}{l}9.73 \\
(6.02)\end{array}$ & $\begin{array}{c}9.62 \\
(6.09)\end{array}$ & $0.036^{\ddagger}$ & - & 0.495 & 0.201 \\
\hline & Muscle mass & $\begin{array}{c}43.45 \\
(17.49)\end{array}$ & $\begin{array}{c}43.35 \\
(17.34)\end{array}$ & $\begin{array}{l}39.36 \\
(16.11)\end{array}$ & $\begin{array}{c}38.98 \\
(15.87)\end{array}$ & $0.667^{*}$ & 0.008 & 0.074 & 0.199 \\
\hline & $\begin{array}{l}\text { Waist } \\
\text { circumference }\end{array}$ & $\begin{array}{l}100.54 \\
(16.02)\end{array}$ & $\begin{array}{l}92.67 \\
(15.16)\end{array}$ & $\begin{array}{l}100.23 \\
(17.75)\end{array}$ & $\begin{array}{l}97.35 \\
(19.55)\end{array}$ & $0.200 *$ & 0.070 & 0.697 & 0.392 \\
\hline \multirow[t]{9}{*}{ Physical fitness } & $\begin{array}{l}\text { Plate Tapping } \\
\text { Test speed of limb } \\
\text { movement }\end{array}$ & $\begin{array}{c}38.22 \\
(14.8 I)\end{array}$ & $\begin{array}{c}33.44 \\
(11.07)\end{array}$ & $\begin{array}{l}28.91 \\
(6.03)\end{array}$ & $\begin{array}{l}28.53 \\
(9.18)\end{array}$ & $0.045^{\dagger}$ & - & 0.867 & 0.078 \\
\hline & $\begin{array}{l}\text { Handgrip Test } \\
\text { static arm strength }\end{array}$ & $\begin{array}{l}23.67 \\
(6.89)\end{array}$ & $\begin{array}{l}25.42 \\
(5.53)\end{array}$ & $\begin{array}{l}22.38 \\
(5.91)\end{array}$ & $\begin{array}{l}23.92 \\
(6.45)\end{array}$ & $0.837^{*}$ & 0.002 & 0.618 & 0.693 \\
\hline & $\begin{array}{l}\text { Shuttle Run running } \\
\text { speed and agility }\end{array}$ & $\begin{array}{l}35.42 \\
(12.55)\end{array}$ & $\begin{array}{l}31.62 \\
(6.32)\end{array}$ & $\begin{array}{l}33.01 \\
(5.69)\end{array}$ & $\begin{array}{l}35.31 \\
(9.06)\end{array}$ & $0.014^{\ddagger}$ & - & 0.478 & 0.508 \\
\hline & $\begin{array}{l}\text { Flamingo Balance } \\
\text { Test }\end{array}$ & $\begin{array}{l}6.08 \\
(11.09)\end{array}$ & $\begin{array}{c}9.92 \\
(12.53)\end{array}$ & $\begin{array}{l}3.31 \\
(8.20)\end{array}$ & $\begin{array}{l}1.69 \\
(6.10)\end{array}$ & $0.477^{\ddagger}$ & - & 0.372 & 0.228 \\
\hline & $\begin{array}{l}\text { Sit and Reach } \\
\text { Test flexibility }\end{array}$ & $\begin{array}{l}34.80 \\
(7.45)\end{array}$ & $\begin{array}{l}36.92 \\
(7.22)\end{array}$ & $\begin{array}{l}29.96 \\
(11.75)\end{array}$ & $\begin{array}{c}29.46 \\
(10.53)\end{array}$ & $0.027^{*}$ & 0.195 & 0.818 & 0.170 \\
\hline & $\begin{array}{l}\text { Standing Broad } \\
\text { Jump explosive } \\
\text { leg power }\end{array}$ & $\begin{array}{l}82.67 \\
(31.52)\end{array}$ & $\begin{array}{l}99.33 \\
(29.49)\end{array}$ & $\begin{array}{l}88.04 \\
(44.02)\end{array}$ & $\begin{array}{c}90.69 \\
(35.20)\end{array}$ & $0.003^{*}$ & 0.319 & 1.691 & 0.235 \\
\hline & $\begin{array}{l}\text { 30-Sec Sit-Ups } \\
\text { trunk strength }\end{array}$ & $\begin{array}{l}7.17 \\
(5.51)\end{array}$ & $\begin{array}{l}8.00 \\
(5.36)\end{array}$ & $\begin{array}{r}9.69 \\
(5.44)\end{array}$ & $\begin{array}{c}7.69 \\
(5.22)\end{array}$ & $0.040^{\dagger}$ & - & 0.271 & 0.585 \\
\hline & $\begin{array}{l}\text { Bent Arm Hang } \\
\text { muscular endurance }\end{array}$ & $\begin{array}{l}1.09 \\
(2.94)\end{array}$ & $\begin{array}{c}3.33 \\
(5.21)\end{array}$ & $\begin{array}{c}0.77 \\
(1.79)\end{array}$ & $\begin{array}{l}1.16 \\
(2.29)\end{array}$ & $0.086^{\ddagger}$ & - & 0.533 & 0.285 \\
\hline & $\begin{array}{l}\text { Six-Minute Walk } \\
\text { aerobic endurance }\end{array}$ & $\begin{array}{l}438.52 \\
(70.98)\end{array}$ & $\begin{array}{l}512.63 \\
(86.00)\end{array}$ & $\begin{array}{l}468.60 \\
(104.83)\end{array}$ & $\begin{array}{l}446.73 \\
(111.02)\end{array}$ & $0.005^{*}$ & 0.291 & 1.020 & 0.265 \\
\hline \multirow[t]{4}{*}{ Motor efficiency } & $\begin{array}{l}\text { Beanbag Overhead } \\
\text { Throw right hand } \\
\text { coordination }\end{array}$ & $\begin{array}{l}5.17 \\
(3.76)\end{array}$ & $\begin{array}{l}6.67 \\
(3.11)\end{array}$ & $\begin{array}{l}6.69 \\
(3.38)\end{array}$ & $\begin{array}{c}5.23 \\
(2.89)\end{array}$ & $0.150 *$ & 0.088 & 0.591 & 0.478 \\
\hline & $\begin{array}{l}\text { Beanbag Overhead } \\
\text { Throw left hand } \\
\text { coordination }\end{array}$ & $\begin{array}{c}6.92 \\
(3.53)\end{array}$ & $\begin{array}{c}6.67 \\
(3.37)\end{array}$ & $\begin{array}{l}8.15 \\
(3.76)\end{array}$ & $\begin{array}{l}5.38 \\
(3.15)\end{array}$ & $0.083^{*}$ & 0.125 & 0.010 & 0.635 \\
\hline & $\begin{array}{l}\text { Bruininks-Oseretsky } \\
\text { Response Speed } \\
\text { Subtest }\end{array}$ & $\begin{array}{c}3.25 \\
(2.22)\end{array}$ & $\begin{array}{c}4.67 \\
(2.8 I)\end{array}$ & $\begin{array}{c}4.31 \\
(2.10)\end{array}$ & $\begin{array}{c}4.77 \\
(2.17)\end{array}$ & $0.265^{*}$ & 0.054 & 0.576 & 0.276 \\
\hline & $\begin{array}{l}\text { Timed Up \& Go } \\
\text { Test functional } \\
\text { mobility }\end{array}$ & $\begin{array}{l}7.03 \\
(\mathrm{I} .1 \mathrm{I})\end{array}$ & $\begin{array}{l}6.12 \\
(0.50)\end{array}$ & $\begin{array}{l}7.01 \\
(1.40)\end{array}$ & $\begin{array}{c}6.76 \\
(1.46)\end{array}$ & $0.049^{\dagger}$ & - & 1.218 & 0.148 \\
\hline
\end{tabular}

${ }^{\star}$ Mixed ANOVA group by time interaction.

${ }^{\dagger}$ Student's t-test for change scores.

${ }^{\ddagger}$ Mann-Whitney U test for change scores.

(C) 2017 MENCAP and International Association of the Scientific Study of Intellectual and Developmental Disabilities and John Wiley \& Sons Ltd 
upper limb coordination and manual dexterity (Berg et al. 2012).

There is clearly growing evidence supporting the effectiveness of exergames on physical fitness-related outcomes for people with DS. Thereby, it is important to notice that this is the first study that found significant effects of an exergame intervention on aerobic endurance of people with DS. The withingroup effect on the Wii-intervention group was large ( $d=0.982$ ), which is quite significant as there is some controversy regarding exercise and cardiorespiratory fitness in people with DS. Andriolo et al. (2010) stated that there was no sufficient evidence to demonstrate that aerobic exercise improves cardiorespiratory fitness in individuals with DS. Conversely, Dodd \& Shields (2005) had opposite findings, suggesting that aerobic exercise could increase several cardiorespiratory fitness outcomes (peak oxygen consumption, peak minute ventilation, time to exhaustion and maximal workload). There is also evidence from adolescents with DS suggesting that engaging in moderate-to-vigorous physical activity is associated with enhanced cardiorespiratory fitness measured by peak rate of oxygen consumption and maximum heart rate (Matute-Llorente et al. 2013). Thus, it is clear that our findings are extremely relevant and may suggest that exergames can be an important alternative to improve health-related physical fitness, as aerobic capacity is strongly associated with cardiovascular disease and all-cause mortality (Sui et al. 2007; Kodama et al. 2009; Després 2016).

Moreover, in our trial, there were also significant increases in muscular strength measures. Metaanalytic findings support strength training for people with DS, and there is a wide range of training procedures that have proven to be effective ( $\mathrm{Li}$ et al. 20I3). However, our findings suggest that Wii-based exercise can be an effective alternative to improve muscular strength, especially in the lower extremities where moderate effects were observed $(d=0.570)$. This is particularly important as there are several studies reporting reduced muscle strength on knee flexors and extensors as well as on hip abductors in people with DS compared with healthy controls (Pitetti et al. I992; Angelopoulou et al. 2000; Mercer \& Lewis 200I).

Interestingly enough, there is evidence suggesting that lower extremity strength is closely associated with cardiorespiratory fitness, which may help to understand our two major findings regarding physical fitness (K. H. Pitetti \& Boneh I995). Furthermore, there is evidence suggesting that daily living tasks and gait performance in individuals with DS are closely related to both lower extremity strength and aerobic capacity (Galli et al. 2008b; Cowley et al. 20I0; Galli et al. 2010). These assumptions may help us to understand the large effects observed in our trial regarding functional mobility ( $d=$ I.I09). Functional mobility is reduced in children and adolescents with DS compared with typically developing individuals (Nicolini-Panisson \& Donadio 2014), but our findings suggested that exergames may allow attenuating these deficits by improving the underlying physical fitness impairments.

It is also worth to mention the almost significant decrease in body weight observed in the experimental group in comparison with the control group, a similar result to the Wii plus aerobic exercise trial from Lin \& Wuang (20I2). There was also a significant difference in visceral fat change score favouring the experimental group, further suggesting that the Wii-based exercise program may be effective to promote changes in anthropometric measures. There are several studies reporting no changes in body composition outcomes after exercise in DS, including body weight, BMI, skinfold measures and body fat (Varela et al. 200I; Rimmer et al. 2004; Ulrich et al. 20II). Only the exercise training program from González-Agüero et al. (20II) allowed a decrease in total fat and improvement in lean masses. Thereby, the marginal findings regarding anthropometric measures in our study are no surprise, although future trials should explore whether increased dosage in Wii protocols could actually allow for changes in body composition.

Although our study had major findings, the small sample size may have limited the power to detect significant differences in other physical fitness outcomes, especially body composition. The selected outcome measures for physical fitness are another important topic when addressing our findings. The Eurofit Test Battery is a reliable tool to assess and discriminate the performance levels of physical fitness in patients with IDs (MacDonncha et al. I999; Skowronski et al. 2009). Specifically, the field-based Six-Minute Walk Test has also been used to assess aerobic capacity in this population (Mosso et al. 20II). However, according to the American College

(C) 2017 MENCAP and International Association of the Scientific Study of Intellectual and Developmental Disabilities and John Wiley \& Sons Ltd 
of Sports Medicine (2009), maximal oxygen uptake is considered the most reliable measure of cardiorespiratory fitness. There is a wide range of validated laboratory and field tests to assess aerobic capacity in people with DS. Future trials should select gold standard measures as the reliability of cardiorespiratory fitness assessment is crucial for exercise prescription (Seron \& Greguol 20I4). Our positive findings on functional mobility also leave room to wonder if Wii-based exercise can improve performance on more demanding everyday tasks, and future trials should explore other functional-related outcomes. Finally, the role of Wii-based exercise intensity and dosage on physical fitness of people with DS is yet to be understood as most protocols until now have used similar designs. Thereby, the effects of long-term and high-intensity exergame training may also be explored by researchers.

\section{Conclusion}

Our findings suggested that Wii-based exercise can be an effective tool to improve physical fitness, functional mobility and motor proficiency of adults with DS, including crucial measures such as aerobic capacity and lower limb strength. People with DS present higher all-cause mortality rates and increased risk of developing cardiovascular diseases, which reinforces the need to develop exercise interventions that effectively engages this population and improves their physical fitness. Thereby, exergames using Wii Fit or other equipment can be appealing alternatives for adults with DS to engage in regular physical activity as the required games are fun and enjoyable and the equipment is inexpensive and can be set up at home.

\section{References}

American College of Sports Medicine (2009) ACSM's Guidelines for Exercise Testing and Prescription, 8th edn. Lippincott, Williams \& Wilkins, Baltimore.

Andriolo R. B., El Dib R. P., Ramos L., Atallah A. N. \& da Silva E. M. (2010) Aerobic exercise training programmes for improving physical and psychosocial health in adults with Down syndrome. Cochrane Database of Systematic Reviews, CDoo5176. https://doi.org/10.1002/14651858. CDoo5176.pub4.

Angelopoulou N., Matziari C., Tsimaras V., Sakadamis A., Souftas V. \& Mandroukas K. (2000) Bone mineral density and muscle strength in young men with mental retardation (with and without Down syndrome). Calcified Tissue International 66, I76-80.

Baynard T., Pitetti K. H., Guerra M., Unnithan V. B. \& Fernhall B. (2008) Age-related changes in aerobic capacity in individuals with mental retardation: a $20-\mathrm{yr}$ review. Medicine and Science in Sports and Exercise 40, 1984-9.

Berg P., Becker T., Martian A., Primrose K. D. \& Wingen J. (20I2) Motor control outcomes following Nintendo Wii use by a child with Down syndrome. Pediatric Physical Therapy 24, 78-84.

Bertapelli F., Pitetti K., Agiovlasitis S. \& Guerra-Junior G. (20I6) Overweight and obesity in children and adolescents with Down syndrome-prevalence, determinants, consequences, and interventions: a literature review. Research in Developmental Disabilities 57, I8I-92.

Bruininks R. (1978) Bruininks-Oseretsky Test of Motor Proficiency-Examiner's Manual. American Guidance Service, Circle Pines, MN.

Campos C., Mesquita F., Marques A., Trigueiro M. J., Orvalho V. \& Rocha N. B. F. (2015) Feasibility and acceptability of an exergame intervention for schizophrenia. Psychology of Sport and Exercise 19, 50-8.

Campos C., Rocha N. B., Lattari E., Paes F., Nardi A. E. \& Machado S. (2016) Exercise-induced neuroprotective effects on neurodegenerative diseases: the key role of trophic factors. Expert Review of Neurotherapeutics I6, 723-34.

Carmeli E., Ariav C., Bar-Yossef T., Levy R. \& Imam B. (20I2) Movement skills of younger versus older adults with and without Down syndrome. Research in Developmental Disabilities 33, I65-7I.

Carmeli E., Bar-Yossef T., Ariav C., Levy R. \& Liebermann D. G. (2008) Perceptual-motor coordination in persons with mild intellectual disability. Disability and Rehabilitation 30, 323-9.

Carmeli E., Barchad S., Lenger R. \& Coleman R. (2002) Muscle power, locomotor performance and flexibility in aging mentally-retarded adults with and without Down's syndrome. Fournal of Musculoskeletal and Neuronal Interactions 2, 457-62.

Chiu H. C., Ada L. \& Lee H. M. (20I4) Upper limb training using Wii Sports Resort for children with hemiplegic cerebral palsy: a randomized, single-blind trial. Clinical Rehabilitation 28, IOI5-24.

Cioni M., Cocilovo A., Di Pasquale F., Araujo M. B., Siqueira C. R. \& Bianco M. (1994) Strength deficit of knee extensor muscles of individuals with Down syndrome from childhood to adolescence. American Fournal of Mental Retardation 99, I66-74.

Connolly B. H. \& Michael B. T. (I986) Performance of retarded children, with and without Down syndrome, on the Bruininks Oseretsky Test of Motor Proficiency. Physical Therapy 66, 344-8.

(C) 2017 MENCAP and International Association of the Scientific Study of Intellectual and Developmental Disabilities and 
V. Silva et al. - Wii exercise adult Down syndrome

Cowley P. M., Ploutz-Snyder L. L., Baynard T., Heffernan K., Jae S. Y., Hsu S. et al. (2010) Physical fitness predicts functional tasks in individuals with Down syndrome. Medicine and Science in Sports and Exercise 42, 388-93.

de Graaf G., Vis J. C., Haveman M., van Hove G., de Graaf E. A. B., Tijssen J. G. P. et al. (20II) Assessment of prevalence of persons with Down syndrome: a theorybased demographic model. Fournal of Applied Research in Intellectual Disabilities 24, 247-62.

Després J. P. (2016) Physical activity, sedentary behaviours, and cardiovascular health: when will cardiorespiratory fitness become a vital sign? The Canadian fournal of Cardiology 32, 505-13.

Dodd K. J. \& Shields N. (2005) A systematic review of the outcomes of cardiovascular exercise programs for people with Down syndrome. Archives of Physical Medicine and Rehabilitation 86, 205I-8.

Douris P. C., McDonald B., Vespi F., Kelley N. C. \& Herman L. (20I2) Comparison between Nintendo Wii Fit aerobics and traditional aerobic exercise in sedentary young adults. Fournal of Strength and Conditioning Research 26, $1052-7$.

Fernhall B., Mendonca G. V. \& Baynard T. (2013) Reduced work capacity in individuals with Down syndrome: a consequence of autonomic dysfunction? Exercise and Sport Sciences Reviews 4I, I38-47.

Franco J. R., Jacobs K., Inzerillo C. \& Kluzik J. (20I2) The effect of the Nintendo Wii Fit and exercise in improving balance and quality of life in community dwelling elders. Technology and Health Care 20, 95-II5.

Galli M., Cimolin V., Patti P., Ferrario D., Heaney G., Albertini G. et al. (2010) Quantifying established clinical assessment measures using $3 \mathrm{D}$-movement analysis in individuals with Down syndrome. Disability and Rehabilitation 32, I768-74.

Galli M., Rigoldi C., Brunner R., Virji-Babul N. \& Giorgio A. (2008b) Joint stiffness and gait pattern evaluation in children with Down syndrome. Gait and Posture 28, 502-6.

Galli M., Rigoldi C., Mainardi L., Tenore N., Onorati P. \& Albertini G. (2008a) Postural control in patients with Down syndrome. Disability and Rehabilitation 30, I274-8.

González-Agüero A., Vicente-Rodríguez G., GómezCabello A., Ara I., Moreno L. A. \& Casajús J. A. (20II) A combined training intervention programme increases lean mass in youths with Down syndrome. Research in Developmental Disabilities 32, 2383-8.

González-Agüero A., Vicente-Rodríguez G., Moreno L. A., Guerra-Balic M., Ara I. \& Casajús J. A. (2010) Health-related physical fitness in children and adolescents with Down syndrome and response to training. Scandinavian fournal of Medicine and Science in Sports 20, 716-24.

Hammond J., Jones V., Hill E. L., Green D. \& Male I. (20I4) An investigation of the impact of regular use of the Wii Fit to improve motor and psychosocial outcomes in children with movement difficulties: a pilot study. Child: Care, Health and Development 40, I65-75.

Hardee J. P. \& Fetters L. (20I7) The effect of exercise intervention on daily life activities and social participation in individuals with Down syndrome: a systematic review. Research in Developmental Disabilities 62, 8I-I03.

Horvat M., Pitetti K. H. \& Croce R. (1997) Isokinetic torque, average power, and flexion/extension ratios in nondisabled adults and adults with mental retardation. Fournal of Orthopaedic and Sports Physical Therapy 25, 395-9.

Hsu J. K., Thibodeau R., Wong S. J., Zukiwsky D., Cecile S. \& Walton D. M. (20II) A "Wii" bit of fun: the effects of adding Nintendo Wii ((R)) Bowling to a standard exercise regimen for residents of long-term care with upper extremity dysfunction. Physiotherapy Theory and Practice 27, I85-93.

Jaarsma T., Klompstra L., Ben Gal T., Boyne J., Vellone E., Back M. et al. (2015) Increasing exercise capacity and quality of life of patients with heart failure through Wii gaming: the rationale, design and methodology of the HFWii study; a multicentre randomized controlled trial. European fournal of Heart Failure 17, 743-8.

Jelsma D., Geuze R. H., Mombarg R. \& Smits-Engelsman B. C. (20I4) The impact of Wii Fit intervention on dynamic balance control in children with probable developmental coordination disorder and balance problems. Human Movement Science 33, 404-18.

Jiménez L., Cerda J., Alberti G. \& Lizama M. (2015) High rates of overweight and obesity in Chilean children with Down syndrome. Revista Médica de Chile I43, 45I-8.

Jung D. I., Ko D. S. \& Jeong M. A. (2015) Kinematic effect of Nintendo Wii(TM) sports program exercise on obstacle gait in elderly women with falling risk. Fournal of Physical Therapy Science 27, I397-400.

Kodama S., Saito K., Tanaka S., Maki M., Yachi Y., Asumi M. et al. (2009) Cardiorespiratory fitness as a quantitative predictor of all-cause mortality and cardiovascular events in healthy men and women: a meta-analysis. $\mathcal{F} A M A$ 30I, 2024-35.

Lanningham-Foster L., Foster R. C., McCrady S. K., Jensen T. B., Mitre N. \& Levine J. A. (2009) Activitypromoting video games and increased energy expenditure. The Fournal of Pediatrics 154, 819-23.

Lee H. H., Emerson J. A. \& Williams D. M. (2016) The exercise-affect-adherence pathway: an evolutionary perspective. Frontiers in Psychology 7, I285.

LeGear T., LeGear M., Preradovic D., Wilson G., Kirkham A. \& Camp P. G. (2016) Does a Nintendo Wii exercise program provide similar exercise demands as a traditional pulmonary rehabilitation program in adults with COPD? The Clinical Respiratory fournal 10, 303-IO.

Lewis C. L. \& Fragala-Pinkham M. A. (2005) Effects of aerobic conditioning and strength training on a child with Down syndrome: a case study. Pediatric Physical Therapy I7, 30-6.

(C) 2017 MENCAP and International Association of the Scientific Study of Intellectual and Developmental Disabilities and 
Li C., Chen S., Meng How Y. \& Zhang A. L. (2013) Benefits of physical exercise intervention on fitness of individuals with Down syndrome: a systematic review of randomizedcontrolled trials. International fournal of Rehabilitation Research 36, I87-95.

Lin H. C. \& Wuang Y. P. (2012) Strength and agility training in adolescents with Down syndrome: a randomized controlled trial. Research in Developmental Disabilities 33, 2236-44.

Lipsey M \& Wilson D (200I) Practical meta-analysis. Sage, Thousand Oaks, CA.

MacDonncha C., Watson A. S., McSweeney T. \& O'Donovan D. (I999) Reliability of Eurofit physical items for adolescent males with and without mental retardation. Adapted Physical Activity Quarterly I6, 86-95.

Matute-Llorente A., González-Agüero A., Gómez-Cabello A., Vicente-Rodríguez G. \& Casajús J. A. (2013) Physical activity and cardiorespiratory fitness in adolescents with Down syndrome. Nutrición Hospitalaria 28, II II-5.

Mendonca G. V., Pereira F. D. \& Fernhall B. (2010) Reduced exercise capacity in persons with Down syndrome: cause, effect, and management. Therapeutics and Clinical Risk Management 6, 60I-10.

Mercer V. S. \& Lewis C. L. (200I) Hip abductor and knee extensor muscle strength of children with and without Down syndrome. Pediatric Physical Therapy 13, 18-26.

Morris S. B. \& DeShon R. P. (2002) Combining effect size estimates in meta-analysis with repeated measures and independent-groups designs. Psychological Methods 7, I05-25.

Mosso C., Santander P., Pettinelli R., Veldes G., Celis B. \& Espejo S. (20II) Evaluación de una intervención en actividad física en niños con síndrome de Down. Revista Chilena de Pediatría 82, 23I I-8.

Nicolini-Panisson R. D. \& Donadio M. V. (2014) Normative values for the Timed ' $\mathrm{Up}$ and Go' test in children and adolescents and validation for individuals with Down syndrome. Developmental Medicine and Child Neurology 56, 490-7.

Nilsagard Y. E., Forsberg A. S. \& von Koch L. (2013) Balance exercise for persons with multiple sclerosis using Wii games: a randomised, controlled multi-centre study. Multiple Sclerosis 19, 209-I6.

Oja P. \& Tuxworth B. (1995) Eurofit for Adults. Assessment of Health-Related Fitness. Council of Europe-UKK Institute, Tampere, Strasbourg.

Park J., Lee D. \& Lee S. (20I4) Effect of virtual reality exercise using the Nintendo Wii Fit on muscle activities of the trunk and lower extremities of normal adults. fournal of Physical Therapy Science 26, 27I-3.

Pitetti K., Baynard T. \& Agiovlasitis S. (2013) Children and adolescents with Down syndrome, physical fitness and physical activity. Fournal of Sport and Health Science 2, 47-57.
Pitetti K. H. \& Boneh S. (1995) Cardiovascular fitness as related to leg strength in adults with mental retardation. Medicine and Science in Sports and Exercise 27, 423-8.

Pitetti K. H., Climstein M., Mays M. J. \& Barrett P. J. (1992) Isokinetic arm and leg strength of adults with Down syndrome: a comparative study. Archives of Physical Medicine and Rehabilitation 73, 847-50.

Podsiadlo D. \& Richardson S. (I99I) The Timed "Up \& Go": a test of basic functional mobility for frail elderly persons. Fournal of the American Geriatrics Society 39, I42-8.

Presson A. P., Partyka G., Jensen K. M., Devine O. J., Rasmussen S. A., McCabe L. L. et al. (2013) Current estimate of Down syndrome population prevalence in the United States. Fournal of Pediatrics 163, II63-8.

Rigoldi C., Galli M., Mainardi L., Crivellini M. \& Albertini G. (20II) Postural control in children, teenagers and adults with Down syndrome. Research in Developmental Disabilities 32, 170-5.

Rimmer J. H., Heller T., Wang E. \& Valerio I. (2004) Improvements in physical fitness in adults with Down syndrome. American fournal of Mental Retardation 109, I65-74.

Seron B. B. \& Greguol M. (2014) Assessment protocols of maximum oxygen consumption in young people with Down syndrome- a review. Research in Developmental Disabilities 35, 676-85.

Shields N., Taylor N. F. \& Dodd K. J. (2008) Effects of a community-based progressive resistance training program on muscle performance and physical function in adults with Down syndrome: a randomized controlled trial. Archives of Physical Medicine and Rehabilitation 89, I215-20.

Skowronski W., Horvat M., Nocera J., Roswal G. \& Croce R. (2009) Eurofit special: European fitness battery score variation among individuals with intellectual disabilities. Adapted Physical Activity Quarterly 26, 54-67.

Sui X., LaMonte M. J. \& Blair S. N. (2007) Cardiorespiratory fitness as a predictor of nonfatal cardiovascular events in asymptomatic women and men. American fournal of Epidemiology 165, I413-23.

Tatla S. K., Radomski A., Cheung J., Maron M. \& Jarus T. (20I4) Wii-habilitation as balance therapy for children with acquired brain injury. Developmental Neurorehabilitation $\mathbf{1 7}$, I-5.

Ulrich D. A., Burghardt A. R., Lloyd M., Tiernan C. \& Hornyak J. E. (20II) Physical activity benefits of learning to ride a two-wheel bicycle for children with Down syndrome: a randomized trial. Physical Therapy 9I, I463-77.

van Gameren-Oosterom H. B., van Dommelen P., Schönbeck Y., Oudesluys-Murphy A. M., van Wouwe J. P. \& Buitendijk S. E. (2012) Prevalence of overweight in Dutch children with Down syndrome. Pediatrics 130, eI520-eI526.

Varela A. M., Sardinha L. B. \& Pitetti K. H. (200I) Effects of an aerobic rowing training regimen in young adults with

(C) 2017 MENCAP and International Association of the Scientific Study of Intellectual and Developmental Disabilities and 
V. Silva et al. - Wii exercise adult Down syndrome

Down syndrome. American fournal of Mental Retardation I06, I35-44.

Williams D. M. (2008) Exercise, affect, and adherence: an integrated model and a case for self-paced exercise.

fournal of Sport and Exercise Psychology 30, 471-96.

Wuang Y. \& Su C. Y. (20I2) Patterns of participation and enjoyment in adolescents with Down syndrome. Research in Developmental Disabilities 33, 84I-8.

Wuang Y. P., Chiang C. S., Su C. Y. \& Wang C. C. (20II) Effectiveness of virtual reality using Wii gaming technology in children with Down syndrome. Research in Developmental Disabilities 32, 312-2 I.

Yuen H. K., Breland H. L., Vogtle L. K., Holthaus K., Kamen D. L. \& Sword D. (20I3) The process associated with motivation of a home-based Wii Fit exercise program among sedentary African American women with systemic lupus erythematosus. Disability and Health fournal 6, 63-8.

Accepted 26 April 2017

(C) 20I7 MENCAP and International Association of the Scientific Study of Intellectual and Developmental Disabilities and John Wiley \& Sons Ltd 